This is the accepted manuscript of the article, which has been published in Journal of

Early Childhood Literacy. https://doi.org/10.1177/1468798419838576

Pirjo Kulju \& Marita Mäkinen

\title{
Phonological strategies and peer scaffolding in digital literacy game-playing sessions in a Finnish Pre-Primary class
}

\begin{abstract}
This study explored what kind of phonological strategies are used by children and how they scaffold each other while they solve tasks in a digital literacy game. The theoretical basis of this study lies in Vygotsky's thoughts on the role of social interaction in learning and in the concept of peer scaffolding. The data included eight videotaped game-playing sessions conducted in small groups in a Finnish pre-primary class with six-year-old children. The analysis was carried out in two phases. Based on a qualitative content analysis of the peer-scaffolding episodes $(\mathrm{N}=363)$, it was found that the Finnishspeaking children used several types of phonological strategies - such as syllabification of words, phonological processing and the production of letter names in solving wordand syllable-level game tasks. Furthermore, a microgenetic analysis of the episodes showed that the six-year-olds displayed emerging peer-scaffolding patterns, such as initiation, responding, modelling and expanding. The results illustrate the pedagogical potential of digital literacy games in the context of social interaction and peer scaffolding.

\section{Key words}

Literacy, digital game, scaffolding, peer scaffolding, phonology

\section{Introduction}

As the textual environment has drastically changed due to the development of digital technology, current trends in literacy research emphasize the multifaceted and multimodal nature of meaning-making (e.g. Kress, 2003; Kalantzis \& Cope, 2012). Reading is also connected to social and cultural contexts, and it involves constant interaction between the text and reader; however, as pointed out by Walsh (2006), this interaction does not occur without what is traditionally referred to as 'decoding', which includes using strategies, such as word recognition and recognition of graphic, morphemic and phonemic patterns (Walsh, 2006). 
Parental support in the home environment sustains children's knowledge on letters and sounds, and then they become more aware of alphabetic principles at school. In the Finnish educational system, the children start pre-primary school at age six, and more systematic reading instruction begins in the first grade at age seven. In Finnish, the process of learning to decode written text into sounds, words and meanings is not as complex as in English due to a shallow orthography. That is, orthography consists of regular grapheme-phoneme correspondences (Seymour, Aro and Erskine, 2003). In fact, Finnish children learn basic reading skills quickly (e.g., Aro \& Wimmer, 2003), and approximately one third of the children can read when they start the first class (Lerkkanen, 2003; Torppa et al., 2013). Our target group, six-year-old pre-primary schoolers, is interesting because at this age most of them are just learning basic decoding skills. Despite extensive, longitudinal studies of Finnish childrens' language development and predictors of early reading skills (e.g. Lyytinen et al., 2015; Silvén et al., 2003; Lerkkanen et al., 2004), there is a limited number of qualitative, linguistic analyses on the phonological processes the child confronts when learning to decode. However, (Mäkinen, 2002) has shown that tasks concentrating on syllables and word initial segments support early reading skills in Finnish. The importance of taking into account language specific features has also been pointed out by Huemer et al. (2010), who showed that repeated reading of syllables increased reading speed among Finnish children with poor reading skills.

In this study, we explore how children support each other in developing phonological strategies in a shared digital literacy game situation in terms of peer interaction and scaffolding. Vygotsky's (1962) sociocultural theory of human learning through interaction has strongly influenced current pedagogical thinking, as changes in literacy practices have led teachers to become increasingly interested in how they can support children in literacy learning. At the core of Vygotsky's work is the idea that learning and development cannot be understood by studying only the individual; rather, they can be understood only through analysing the development of higher order functions as intertwined with complex processes of social interaction. Through participating in learning activities requiring both cognitive and communicative functions, children are encouraged to use these functions in ways that nurture and guide their learning (cf. Gallimore \& Tharp, 1990; Vygotsky, 1978.)

Since Vygotsky emphasises practising skills together with others, we base our analysis on the theoretical concept of scaffolding, specifically, peer scaffolding. Scaffolding is related to the notion of an 'expert' (i.e. an adult, teacher, tutor, class aide or advanced peer), who is crucial to the learning process. This arises from Vygotsky's (1978) notion of a child's potential for development or what is known as the Zone of Proximal Development (ZPD), which is defined as follows: 'The distance between the actual development as determined by independent problem solving and level of potential development as determined through problem solving under adult guidance or in collaboration with more capable peers' (p. 86).

Wood et al. (1976) have proposed the metaphor of 'scaffolding' to describe the instruction or support processes whereby an expert or more advanced (less novice) peer helps somebody who is less of an expert (a novice). Scaffolding is crucial because it 
allows children to carry out tasks that would otherwise be beyond their abilities. In this regard, Kozulin (1990) has pointed out that for Vygotsky, learning and development do not precede instruction but depend on it; therefore, the difference between actual and potential development is crucial from the perspective of scaffolding.

Influenced by Wood et al. (1976), many scaffolding approaches and empirical studies have emerged (cf. Belland, Walker \& Kim, 2017). In current research on interactive learning environments, the concept of scaffolding has been extended to refer to aspects based on computer-assisted learning environments, which help learners in making progress in task solving (e.g. Devolder et al., 2012; Pifarre \& Cobos, 2010: Reiser, 2004). The software could provide prompts to encourage students to take further steps, help them to plan and monitor the learning processes (e.g. Azevedo et al., 2004; Kramarski \& Mizrachi, 2006); moreover, they could enable them to work collaboratively and scaffold each other during the learning activities (e.g. Pifarre \& Cobos, 2010). These perspectives are in line with Donato's (1994) ideas of mutual scaffolding, which are based on his research on peer interaction. Several studies have also remarked on the beneficial aspects of mutual or peer scaffolding in learning. Regarding early reading, Griffin (2002) has found out that paired reading is a useful scaffolding technique. Also, Eskelä-Haapanen (2012) has noted that support from peers, such as modelling, is fruitful in early literacy learning. However, it seems that peer scaffolding has not been specifically studied in terms phonological strategies in preschool aged children's literacy learning, let alone in a digital game environment. For this reason, we draw insight for our study from studies related to language and literacy learning in a broader sense. In these studies, scaffolding refers especially to the linguistic and phonological support provided by a teacher or a more advanced peer in clarifying the purpose of the task, providing clear directions, keeping children on task and creating momentum toward for the joy of success (e.g. Bruner, 1990; Donato, 1994; Gibbons, 2002).

Shooshtari and Mir (2014) have illustrated how peer scaffolding can improve L2 learners' writing strategies. They discuss two peer scaffolding activities: 'joint construction' refers to a learning activity wherein a group of students construct a task together with the teacher as a 'mentor'. 'Peer response feedback' is an activity wherein students work in pairs or small groups using prompts provided by the teacher to respond to each other's writing. The results reveal that these types of peer-scaffolding exercises help participants make remarkable progress in both writing quality and strategies (Shooshtari \& Mir, 2014).

Li and Kim (2016) have examined peer scaffolding in L2 writing by analysing language functions, which they divide into two categories - initiating and responding. Initiating refers to proposing new ideas, for example, eliciting, greeting, justifying, requesting, stating or suggesting. Responding relates to reactions to others' ideas, for example, acknowledging, agreeing or elaborating. In addition, they look at strategies such as instructing. In their recent study, Ranjbar and Ghonsooly (2017) analyse language functions on peer scaffolding in collaborative writing; they conclude that learners can engage in more participation, learn evaluative feedback strategies and benefit from their peers. Furthermore, Gnadinger (2008) has explored peer scaffolding at the elementary 
level during collaborative activities. She found that peers provide scaffolding to one another in various ways by questioning, instructing, providing feedback and modelling.

In this study, we explored peer scaffolding in the context of a digital literacy game. Computer applications have indeed shown to support beginning readers (Blok et al., 2002) and to be effective in training at-risk children (e.g. Regtvoort \& van der Leij, 2007) as well as children with reading disabilities (e.g. Jime'nez et al., 2007). The benefits of using GraphoGame, an early literacy game, are also evident in the context of the Finnish language (e.g. Ronimus \& Richardson, 2014; Heikkilä et al., 2013; Pennala et al., 2013; Saine et al., 2011; Lovio et al., 2012). Although the benefits of using (usually individually oriented) digital literacy games seem to be clear - with a growing number of good quality apps being released for practising early literacy skills - we believe that their full potential is still untapped. For instance, Wohlwend (2015) has explored the potential benefits of collaborative play and composing with touch screen apps. This study considers the benefits of collaboration in the use of an educational literacy app focusing on basic literacy skills, which is the most popular type of educational literacy apps (cf. Guernsey et al., 2012).

For the present study, we constructed scaffolding-focused learning activities wherein the children played digital literacy game in pairs or in groups of three. The researcher served as a 'mentor' so that she could indirectly steer and stimulate the joint learning activity. We also followed Li and Kim's (2016) operational definition of scaffolding: the assistance of group members to facilitate the completion of joint tasks. We especially applied the abovementioned language functions (Li \& Kim, 2016) as well as the scaffolding strategies presented in Gnadinger (2008) to analysis the peerscaffolding interactions in digital game-playing sessions among six-year-olds in a preprimary classroom. To conclude, in this interdisciplinary study combining the aspects of linguistics and pedagogy, we sought to answer the following questions with a sample of video-recorded game-playing situations:

What kind of linguistic strategies do children use in solving phonological tasks in digital literacy game playing?

How do the children scaffold each other when playing digital literacy games?

Before discussing our methodology, we will present basic information about the Finnish language and describe the digital game used in this study.

\section{The Finnish language}

Since this study investigates Finnish-speaking six-year-olds in a pre-primary class, we will provide a short description of the Finnish language to better explain the linguistic aspect of this study. Lola Panda, the game used in this study, operates using words and syllables. There are ten basic syllable structures in Finnish: $(\mathrm{C}) \mathrm{V},(\mathrm{C}) \mathrm{VV},(\mathrm{C}) \mathrm{VC}$, (C)VCC and (C)VVC. Each of the syllables is essentially connected to word stress- the main stress in Finnish is fixed on the word-initial syllable and the secondary stress falls on every other syllable after that. Word-initial consonant clusters appear only in 
loanwords, but word-medial consonant sequences are common. In addition, diphthongs are common in syllable structures. The phonological quantity distinction in consonants and in vowels forms minimal pairs such as tuli-tuuli ['fire - wind'], kisa-kissa ['competition - cat']. The quantity distinction is also visibly marked in Finnish orthography, as a short segment is written with one letter and a long segment with two identical letters.

A typical Finnish word is bisyllabic, but long words with multiple syllables are also very common due to a rich derivational system as well as an agglutinative and a fusional morphology, e.g. the bisyllabic loan word auto ['car'] becomes trisyllabic when inflected in the inessive form autossa ['in a car']. The game in this study used individual syllables as well as bi- and multisyllabic words in their basic forms.

In Finnish orthography, the grapheme-phoneme correspondence is regular; phonemes are marked with corresponding single-letter graphemes. Finnish has eight vowel phonemes, /a, e, i, o, u, y, ä, ö/, and thirteen consonants, /p, t, k, d, m, n, y, r, l, s, h, $\mathrm{v}, \mathrm{j} /$. The consonants $/ \mathrm{b} /, \mathrm{g} / \mathrm{and} / \mathrm{f} /$ are used in more recent loanwords. The only exception to the phoneme-grapheme correspondence is $/ \mathrm{y} /$, which is marked with the letter $n$ when short (in front of $k$ ) and as $n g$ when long. (For a description of Finnish phonology, see e.g. Lyytinen et al., 2006; Kulju \& Mäkinen, 2017).

Early reading instruction in Finnish starts at pre-primary education; children are taught that speech can be divided into smaller segments, such as words, sentences and phonemes (NCCP, 2016). Instruction at school is more systematic and it is based on basic units of phonemes, syllables and words following sentences and texts (NCC, 2016); this is seen both in spoken instruction in the classrooms and in $\mathrm{ABC}$ books. Even though single syllables seldom carry meaning, their phonemic construction is carefully examined in early reading and writing instruction in order to support children's language awareness and the understanding of phoneme-grapheme correspondence. In the classroom, words are typically divided into syllables by rhythmically clapping hands, which helps to find syllable borders and to perceive the phonemes in a syllable and a word. This, in turn, provides support for early writing processes (cf. Lehtonen \& Bryant, 2001).

\section{Lola Panda: A Digital Literacy Game}

The app Lola Panda: Lolan tavuviidakko [Lola Panda: Lola's Syllable Jungle] is used in this study and is based on practising a skill, which is common in educational apps (see, Hirsh-Pasek et al., 2015). Lola Panda's syllable game is composed of three levels of increasing difficulty. Each level has several phonological tasks focusing on words and syllables, such as identifying the first, middle or final syllable of a word, or placing the syllables of a word in the correct order. Children solve these tasks by choosing the correct answer from a few choices by tapping the screen.

Rowsell and Wohlwend (2016) have presented a map of participatory literacies in apps. The game used in this study takes advantage of multimodality, as it uses animation, sound, written words and images on the screen - the images are used to illustrate words that the children are supposed to process phonologically, for example, by organising the 
scrambled syllables of a word in the correct order. The game allows a child to choose the level to play, but it is not open-ended; it does not give players the freedom to journey across or move into different story lines. The productive dimension is limited in Lola Panda: it only allows the selection of pre-defined options as a reward at the end of each task. Furthermore, the app does not support connectedness; it does not connect users to digital resources and does not enable sharing on social networks. The pleasure of playing is individual, and it is difficult to assess to what extent Lola Panda provides this pleasure; however, the children in this study seemed to enjoy playing it.

The multiplayer dimension mentioned in Rowsell and Wohlwend's (2016) app map is worth considering in the present study. Apps supporting this dimension encourage a group of players to negotiate their next move and to communicate while they move ahead in the game. Although Lola Panda does not enable multiplayer interactions as such, the game can also be played on a touch screen TV, which enabled us to view the interactions as the children played the game in pairs or in groups of three.

\section{Methodology}

In this qualitative study we conducted a two-step analysis, which consisted of both the traditional manifest content analysis of 'the objective, systematic and quantitative description of the manifest content of communication' (Berelson, 1952: 18), and the microgenetic method delving into the process of learning and cognitive change (e.g. Siegler, 2007). We applied the microgenetic method in the observation of 'time of transition' and skill acquisition during the learning events (cf. Belz \& Kinginger, 2003; de Guerrero \& Villamil, 2000; Ranjbar \& Ghonsooly, 2017). The method provided to be a useful tool to understand moment-to-moment learning processes by observing the children's ways of collaborating and scaffolding each other during the digital gameplaying sessions.

\section{Participants}

The study was conducted in a pre-primary class of six-year-olds in a city in southern Finland. Pre-primary education is preparatory education, occurring before the beginning of primary school at the age of seven. The children's reading and writing skills development is supported through play, functional exercises and learning environments, which include multiple opportunities to observe, explore and experiment with spoken and written language (NCCP, 2016: 45). The class in this study had received this type of basic instruction prior the data collection. The class participating in this study comprised of fourteen Finnish-speaking students, ten girls and four boys. The children played the game in pairs or in groups of three (see Table 1).

\section{Data collection}

Written permission for data collection was sought from both the city municipality and from the parents. The data was collected over three days in the spring semester. The children $(\mathrm{N}=14)$ played the Lola Panda syllable game in pairs or in groups of three for 
approximately twenty to thirty minutes. We used the teachers' estimation of the children's early reading skills in forming the pairs and groups so that they included combinations in which all, one or none of the participants showed early reading skills. Reading skill itself was not the focus of the study, rather the strategies and scaffolding interactions. During the game play, it became evident that the children had an initial knowledge of phonological structures even though they were not all classified as 'readers' by the teachers. Some of the children took part in two game-playing sessions. The researcher (first author) led the game-playing sessions in the role of a teacher: At the beginning of each session, she instructed the children to take turns while they played. She also encouraged them to help and support their peers. Such encouragement in play sessions had not been used systematically in the group before.

The play sessions began with the easiest level of the game and progressed to more advanced levels in a suitable time frame for each group of children. The data collection was done in cooperation with the Beiz game studio who have produced the game and provided technical support. The children were familiar with the game, as Beiz had previously provided the game with a touch screen TV in this pre-primary classroom. The play sessions were video recorded using a Canon Legria HFR26 camera and were later transcribed from the videos. The data included eight game-play sessions and a total of 192 minutes of recordings (Table 1).

Table 1. Overview of the videotaped and transcribed data. (Bolded names indicate children with early reading skills based on the teacher's estimation.)

\begin{tabular}{|l|l|l|l|}
\hline Play sessions & $\begin{array}{l}\text { Participants } \\
\text { (pseudonyms) }\end{array}$ & $\begin{array}{l}\text { Length of the video } \\
\text { (play time in minutes } \\
\text { and seconds) }\end{array}$ & $\begin{array}{l}\text { Number of } \\
\text { transcribed episodes }\end{array}$ \\
\hline Video 1 & Leo \& Sara & $19: 17$ & 32 \\
\hline Video 2 & Emilia \& Iida & $20: 16$ & 31 \\
\hline Video 3 & Elli \& Oliver & $26: 57$ & 63 \\
\hline Video 4 & Elsa, Oliver \& Anni & $34: 51$ & 60 \\
\hline Video 5 & $\begin{array}{l}\text { Veera, Emma \& } \\
\text { Daniel }\end{array}$ & $19: 39$ & 53 \\
\hline Video 6 & Sara \& Minea & $20: 52$ & 21 \\
\hline
\end{tabular}




\begin{tabular}{|l|l|l|l|}
\hline Video 7 & Joona, Daniel \& Elli & $30: 49$ & 54 \\
\hline Video 8 & Emilia \& liris & $18: 55$ & $\begin{array}{l}49 \\
\text { TOTAL 363 }\end{array}$ \\
\hline
\end{tabular}

\section{Transcription}

In the transcriptions, the children's interactions during the play were organised into episodes following the rhythm of the game: an episode is a single unit of discourse during which the participants discussed solving one game task (cf. Li \& Kim, 2016). We only transcribed speech related to the phonological tasks - for example, lengthy negotiations regarding taking turns were not transcribed. In addition, we did not transcribe the automatic feedback that the game continuously provided. While playing the game, the children often processed the target words and syllables sound by sound. These specific sections were carefully transcribed with the relevant phonetic marks, such as for an unexceptionally strong stress (') or for the length of a phoneme (::). Additional notes and clarifying remarks were made in brackets to describe actions, such as pointing, clapping hands or tapping the answer on the screen. The transcripts were made by the first author, who has experience in phonetic transcription. After a reasonable period of time, the transcripts of the relevant episodes were again checked by the same researcher. The language of the game play and the discussions was Finnish. For this study, we have translated the examples into English.

\section{Analysis}

The data analysis was carried out in two phases. We began by reading through the transcribed data and classifying the phonological strategies the children used in solving the phonological tasks. In this data-based, qualitative analysis, certain patterns emerged while reading through the date-for example, the syllabification of a word was used several times as a strategy to solve a game's task. The qualitative classification of the linguistic strategies was then quantified to create an overall picture of the strategies the children used.

In the next step, we focused on the peer-to-peer interaction and examined more carefully how the phonological strategies were used in the interaction in terms of peer scaffolding. Through a microgenetic analysis, we discussed and determined the momentby-moment scaffolding strategies used, and applied the theoretic models of peer scaffolding. We chose illustrative examples of these learning events from several pairs in order to point out the patterns of peer scaffolding in the data.

\section{Results}


The children used several types of linguistic and especially phonological strategies in solving the game's tasks. These strategies are summarised in Table 2. In the following section, we will describe the use of each of these strategies; we present illustrative microgenetic analyses of peer-scaffolded episodes in which these strategies came up.

Table 2. Phonological strategies used by small groups in solving syllable-based phonological tasks in a digital literacy game.

\begin{tabular}{|l|l|l|l|}
\hline & $\mathrm{N}=565$ & $\%$ & $\begin{array}{l}\text { Number of children (N }= \\
14) \text { using the strategy }\end{array}$ \\
\hline Production of the first syllable & 123 & 21.8 & 14 \\
\hline Syllabification & 113 & 20.0 & 11 \\
\hline Production of the second or third syllable & 86 & 15.2 & 12 \\
\hline Phonological processing & 53 & 9.4 & 7 \\
\hline Explanation & 49 & 8.7 & 11 \\
\hline Letter names & 44 & 7.8 & 6 \\
\hline Association & 42 & 7.4 & 8 \\
\hline Production of word-initial phoneme & 25 & 4.4 & 6 \\
\hline Stressing a syllable & 15 & 2.7 & 7 \\
\hline Lengthening a phoneme & 15 & 2.7 & 6 \\
\hline
\end{tabular}

\section{Production of individual syllables}

Word-initial syllables were used as a strategy in $21.8 \%$ of the cases, and the production of a syllable later in a word was used in $15.2 \%$ of the cases (Table 2). Isolation of the initial syllable of the multisyllable word has thought to indicate a more explicit level of phonological processing than syllabification which was also among the most common phonological strategies in the present data (Mäkinen, 2002; cf. Hester \& Hodson, 2004). 
Typically, a word-initial syllable was produced when providing the correct solution for a type of task, as demonstrated in Example 1 below. In this episode, Veera initiates interaction (cf. Li \& Kim, 2016) and assists Emma by whispering the correct answer to her (the word-initial syllable $k a$ ). This resembles stating one's ideas as a language function, as suggested by Li \& Kim (2016). Also, Daniel takes part in the discussion by pronouncing and repeating the target word, but this, in fact, does not help in solving the problem, which is to perceive the initial syllable. Then, Emma responds to Veera by clicking the correct answer on the screen, and, finally, Daniel gives feedback by agreeing with Emma and Veera (Li \& Kim, 2016) and confirming her choice.

Example 1

Video 5: Veera, Emma \& Daniel

Game: What is the first syllable of the word kala ['fish'] (syllables provided: $k i, k a, k o$ ).

Veera: $k a$ (whispers the correct word-initial syllable to Emma).

Daniel: kala (repeats the word kala ['fish']).

Emma: (Taps the correct answer.)

Daniel: Yes, that one.

\section{Syllabification}

The data shows that syllabification was one of the most commonly used phonological strategies in solving the game's tasks; $20 \%$ of the strategies used were classified as word syllabification. Of the fourteen children, eleven used syllabification at least to some extent. As syllables are at the core of Finnish word structures and are a key unit in the Lola Panda game, the use of this strategy proved to be fruitful. Syllables are also a key element in early reading instruction (e.g. Huemer, 2010; Mäkinen, 2002). Example 2 below is an illustrative case in which Oliver, who appeared to be very skilled, understands that he can assist his peer with the tasks. The target (loan) word in Finnish pingviini ['penguin'] is rather challenging as it includes the phoneme $/ \mathrm{y} /$, which in Finnish orthography is unexceptionally marked with the two letters $n g$. The task was to place the syllables of the word in the correct order on the screen. In the game, this task was made challenging; four syllables were provided, but only three were part of the correct word form.

At first, Elli does not succeed in solving the task. Then, the researcher provides promts that encourage the children to go on with the task. Oliver responses to this initiation as he realises that Elli needs help. He looks at Elli and does not say anything but illustrates and models the syllable rhythm by clapping his hands thus offering a behavior to be imitated (Gallimore \& Tharp, 1990). While doing this, he looks at Elli and provides wait time (cf. Gnadinger, 2008) for her to complete the task. As Elli still cannot do the task, the researcher continues to encourage her. Oliver expands his assistance and pronounces the syllables along with the clapping. Finally, Elli responds (Li \& Kim, 2016) by tapping the screen. Even though the task proves to be too difficult for Elli, Oliver 
shows explicit modelling (Gnadinger, 2008), during which he illustrates step by step how to perceive the syllables of the word by clapping rhythmically at first and then by adding pronunciation. It may be that clapping is a learned strategy, since it is commonly used in reading instruction (e.g. Eskelä-Haapanen, 2012).

Example 2

Video 3: Elli \& Oliver

Game: Using the given syllables, form the word shown in the picture

(target word: pingviini ['penguin']; syllables provided: $n i$, vii, pin, ping).

(Elli tries to solve the task but fails. After a while, they return to the task.)

Researcher: How would you do this one?

Oliver: (Claps his hands to the rhythm of the syllable without saying anything, simply looks at Elli.)

Elli: (Thinks)

Oliver: bin (claps), vii (claps), (claps).

Researcher: What could be the first syllable?

Oliver: pin (claps), vii (claps), ni (claps), pinviini (claps his hands to the word rhythm, pronounces the syllables and, finally, the whole word).

Elli: (Sighs and taps the wrong syllables).

\section{Phonological processing}

This refers to a strategy in which a child separates the words not only into syllables but into further smaller units while solving the task. This strategy was used in $9.4 \%$ of the cases and was systematically used by one of the participants, Sara. Example 3 below illustrates how she solves the task by separating the individual phonemes and syllables of the given word. The task in this example was to identify the syllables of the word kynttilä ['candle']. Sara produces the word by pronouncing the syllable-initial consonants and syllables. Even though this episode does not include a discussion with her peer, Leo, we believe that by initiating and processing the word out loud, Sara models how she detects the syllables in a given word to Leo. In fact, at the end, Leo follows Sara's phonological processing and completes the word by pronouncing the final syllable. In terms of scaffolding, this is connected to intersubjectivity, in which group members have a shared understanding of the situation and are in tune with each other (Li \& Kim, 2016).

Example 3

Video 1: Leo \& Sara

Game: Can you find the missing syllables for the word shown in the picture? (Target word kynttilä ['candle']; syllable kynt- is given along with the options $l \ddot{a}, t i, t \ddot{a})$.

Sara: $k$, kynt, $t i$ (taps the correct syllable), $l$, lä (taps the correct syllable). 
Leo: $l \ddot{a}$ (pronounces the correct final syllable after Sara has pronounced '1').

\section{Explanation}

Apart from several phonological strategies, $8.7 \%$ of the strategies were classified as explanations. This refers to cases in which the children gave spoken explanations regarding the tasks' solutions. In Example 4 below, Emilia can solve the first two syllables of the given trisyllabic word raketti ['rocket']. However, she runs into trouble in identifying the final syllable and taps the incorrect answer. Iida evaluates her decision and illustrates what the word would sound like with the incorrect final syllable; thus, she indicates that she disagrees (Li \& Kim, 2016) with Emilia's decision. In fact, this resembles instruction and giving a mini-lesson, but the tone is more descriptive than authoritative (cf. Li \& Kim, 2016).

Example 4

\section{Video 2: Emilia \& Iida}

Game: Using the given syllables, form the word shown in the picture (target word: raketti ['rocket']; syllables provided: $t i, r a, r i, k e t$ ).

Emilia: (Taps the correct first syllable $r a$ ).

Emilia: (Taps the correct second syllable ket).

Emilia: (Taps the incorrect final syllable ri) .

Iida: se lukee sit se ois raketri ['but then it reads 'raketri'].

Emilia: (Taps the correct final syllable).

\section{Letter names}

$7.8 \%$ of the strategies used were classified as the production of letter names. As seen in Example 5, producing letter names as a strategy was especially used by Oliver in supporting Elli as he initiates interaction (Li \& Kim, 2016) by pronouncing the initial syllable, but when that does not help, he continues repeating the first syllable. Elli responds to and imitates Oliver, but she cannot identify the right syllable on the screen. Because of this, Oliver expands and elaborates his assistance (Li \& Kim, 2016) by saying the letter names of the first syllable. Letter names differ from the phonological form of the phonemes, but they may help in recognising the correct syllable on the screen. However, in this case, Oliver seems to be frustrated because his support does not seem to help, and he finally taps the correct word-initial syllable himself. As a scaffolding strategy, Oliver's interaction can be seen as parallel to instructing and giving minilessons in an authoritative tone (Li \& Kim, 2016). After this episode and despite his frustration, Oliver continues helping Elli.

Example 5 


\section{Video 3: Oliver \& Elli}

Game: Using the given syllables, form the word shown in the picture

(target word: lapio ['shovel']; syllables provided: la, o, pi, laa).

Oliver: $l a$ (pronounces the first syllable and indicates that it is Elli's turn).

Elli: lapio (repeats the target word).

Oliver: la, lalalalala (repeats the initial syllable).

Elli: lalala (repeats after Oliver).

Oliver: äl $a a$, $\ddot{l} l a a$ (pronounces the letter names $/ 1 /$ and /a/ twice in Finnish).

Elli: Oliver! (commands Oliver using a friendly tone).

Oliver: 'äl 'aa (a bit frustrated).

Oliver: Tämä tässä ['this here'] (points at the correct syllable and taps).

\section{Association}

During the tasks with the children, an interesting strategy emerged showing imagination in connecting certain words or syllables with other words on the basis of their phonological form. This strategy was used by eight children at least once and comprised $7.4 \%$ of the total strategies used. In the data, Oliver used this strategy the most; he was very skilled in forming and expressing these connections. Example 6 below shows a typical association based on a syllable given in a task. In this session, the target syllable was $a i$. In Finnish, the syllable ai (or, repeatedly, aijaijai) is often used to mean 'ouch'; however, in the game, it was not assigned any meaning. Oliver solves the task, and Elli repeats the syllable in its neutral form and claims, or states (Li \& Kim, 2016), that she also knows the answer (this task was easier than some of the others). Then, Oliver expands or elaborates ( $\mathrm{Li} \& \mathrm{Kim}, 2016$ ) his notion from form to meaning by laughing and saying aijaijai mua sattu ['ouch, it hurts']. Elli agrees (Li \& Kim, 2016), imitates him and says $a u$, a variation of 'ouch' in Finnish.

Example 6

Video 3: Elli \& Oliver

Game: Tap the syllable that you hear (target syllable: ai; syllables given: $a a, a u, a i)$.

Oliver: (Taps the correct answer.)

Elli: ai tiesin ['Ai, I knew that'] (repeats the syllable).

Oliver: aijaijai mua sattu ['ouch, it hurts'] (laughs).

Elli: au mua sattu ['ouch, it hurts'] (imitates Oliver).

There were several cases in the data in which individual syllables not carrying any meaning as such were connected to meaningful words, especially by Oliver, e.g. äi $>\ddot{a} i t i$ ['mother'] or au > auto ['car']. In rarer cases, the individual syllables were connected to 
words in which they appeared only later, e.g. ai $>$ samurai ['samurai']. Furthermore, in tasks that presented a whole word and required the perception of its syllables, these syllables were sometimes connected with other words-e.g. the syllable $r a$ from the word kamera ['camera'] was connected to rata ['track']. These examples resemble verbal play in paired reading reported by Griffin (2002). Similarly, in her study, play has a role in creating supportive relationships, which is related to affective involvement ( $\mathrm{Li} \& \mathrm{Kim}$, 2016). By playing, a child who is perhaps not that skilled at first may start to notice the connections between forms and meanings.

\section{Production of word-initial phonemes}

$4.4 \%$ of the strategies used were classified as the production of the word-initial phoneme. This strategy is close to phonological processing, but it has been classified separately, since the word-initial phonemes may be easier to detect than the word-medial phonemes and syllables due to prominent stress position (cf. Bernhardt \& Stemberger, 1998).

Example 7 below shows how Joona can organise the syllables in the correct order. All of the three children in this episode take part in the interaction, indicating both joint construction (Shoostari \& Mir, 2014) and intersubjectivity (Li \& Kim, 2016). Joona, whose turn it is to solve the task, produces the word-initial consonant $r$, which helps in detecting the first syllable $r a$ on the screen. Daniel verifies and elaborates (Li \& Kim, 2016) Joona's notion by expanding the initial consonant into the syllable $r a$, while Joona continues producing the word-initial consonant. All three participants produce a part (ke) of the second syllable (ket), and then Joona taps the correct answer.

\section{Example 7}

\section{Video 7: Joona, Daniel \& Elli}

Game: The syllables are in the wrong order. Can you organise them? (Target word: raketti ['rocket']; syllables provided: ket, $t i, \mathrm{ra}$ ).

Elli: Raketti (repeats 'rocket').

Joona: $r: r$ : (produces the word-initial consonant $r$ at the same time that Elli repeats the target word).

Daniel: Ensimmäinen missä on r:a ['The first one with 'r:a'] (lengthens the phoneme $/ \mathrm{r} /$ ).

Joona: $r::$ (lengthens the phoneme $/ \mathrm{r} /$ at the same time that Daniel comments, then taps the correct first syllable).

Daniel: $k e, k e$.

Joona: ke, ke, ke, ke (repeats parts of the second syllable along with Daniel).

Elli: $k e$ (also points at the correct syllable on the screen at the same time as Daniel and Joona).

Joona: (Taps the correct second syllable). 
Joona: $t i$ (taps the correct final syllable at the same time that Elli points at the syllable).

\section{Stressing a syllable}

In $2.7 \%$ of the cases, the children produced a word with unexceptional stressing. As the word stress in Finnish is usually on the first syllable, this unexceptional stressing marked the child's strategy during the game. In Example 8, Emilia says the correct answer out loud by stressing the syllable. Iiris agrees (Li \& Kim, 2016) and provides feedback (Gnadinger, 2018) by verifying her solution. This type of feedback may encourage and increase affective involvement, although Li \& Kim (2016) characterise the involvement as being expressions of warmth to group members.

Example 8

Video 8: Emilia \& Iiris

Game: Can you find the missing syllable in the word shown in the picture?

(Target word: onki ['fishing rod']; syllables given on the screen: $k i$;

syllables provided: $o n, o l, o k)$.

Emilia: on 'ki (taps the correct answer).

Iiris: Tietysti ['Of course'].

\section{Lengthening a phoneme}

This strategy was used in $2.7 \%$ of the cases. It overlapped with the categories of producing word-initial phonemes and individual syllables in which the phonemes were sometimes lengthened; however, in some cases, as in the example below, it was used as such. This strategy most likely helped the children perceive the phonemes of the word. In the following example, Emilia lengthens the phonemes and finds the solution to the task. While doing this, Iiris quietly imitates her phoneme lengthening, which indicates that Emilia's strategy serves as modelling. Iiris claims to know the right answer, but she provides time to Emilia; however, by claiming this, she may have put pressure on her peer whose turn it was to solve the task. Finally, she gives feedback (Gnadinger, 2008) by verifying Emilia's answer. As a language function, Iiris's interaction also resembles stating one's ideas (Li \& Kim, 2016) rather than just giving positive feedback.

Example 9

Video 8: Emilia \& Iiris

Game: What is the first syllable of the word amme [ 'bathtub']? (Syllables provided: $a k, a i, a m)$.

Emilia: a:mme:: (repeats the target word by lengthening the phonemes; in the background, Iiris quietly imitates her pronunciation).

Iiris: Mää tiedän jo ['I already know'].

Emilia: am'me:: (taps the correct answer). 
Iiris: Mä tarkotin just sitä ['That's what I meant'].

To conclude, we will point out that especially one of the children, Oliver, clearly understood how he could assist his peers in several ways by using his own knowledge of the word structures. He initiated, modelled and elaborated his modelling. After one longer task-solving process, he stated that it 'works out by collaboration'.

\section{Discussion}

The rise of digital technology has provided more options for conducting literacy skills training in schools. As Israelsson (2015: 341) notes, there are a large number of apps available for instruction and for practising early literacy skills - such as letter names and sounds, rhyming, blending and segmenting - but their full potential is still untapped. In this study, we have explored the digital literacy game-playing from both a linguistic and a pedagogical aspect. The qualitative content analysis of the video-recorded game-play sessions showed that the children used several kinds of phonological strategies, such as syllabification and phonological processing, in solving the word- and syllable-based tasks in the game. There were also signs of strategies extending to spoken explanations of word forms or shifting attention from form to word meanings through associations. The found strategies are tied to phonological structure of Finnish-for instance, syllabification resembles the role of syllable rhythm in Finnish phonology. In addition, some of the strategies may be learned in early instruction, such as clapping hands in a syllable rhythm. However, to our knowledge, these types of linguistic strategies have not been documented in digital game environments in Finnish before, and, thus - they together with the aspects of peer scaffolding - may support the further development of learning games.

These strategies were combined with the analysis of peer scaffolding, by which we mean the assistance of group members to facilitate the completion of joint tasks (cf. Li \& Kim 2016). Based on a microgenetic analysis, we identified emerging scaffolding patterns by applying the language functions proposed by Li and Kim (2016) and the scaffolding strategies outlined by Gnadinger (2008). The children typically initiated the scaffolded interactions by modelling the phonological strategy out aloud. Sometimes, when a peer needed more help, a child expanded or elaborated his or her scaffolding by modelling another strategy. Even though we characterize the scaffolding of the six-year olds' as "emerging", modelling has been characterized as a powerful means to assist performance, and, in fact, in educational settings, both teacher and peer models are highly important (Gallimore \& Tharp, 1990).

The interactional discussions in the episodes were overall fairly scarce; children at this age are perhaps not yet able to, or are not used to, expressing their linguistic thinking verbally. On the other hand, the digital literacy game itself may have hindered further discussions, as it automatically proceeded to the next stage after the solution had been tapped. We also did not detect certain scaffolding strategies - such as maintaining the pursuit for the group work's goal or arousing group members' interest in the tasks (Li \& Kim 2106) — in the data probably because the game's sequential tasks kept the young 
children focused. Even though we were able to define only a limited number of peer scaffolding strategies, modelling being the main one, the children seemed to understand the idea of supporting their peers. Thus, working on the Zone of Proximal Development (ZPD) (Vygotsky, 1978) was possible within the digital playing situations. The game, and especially the technical solution of the touch screen TV, served to enhance peer scaffolding, but it would be fruitful if future educational literacy games included more time for pauses and pondering. The educational literacy apps could also be developed to include multiplayer dimensions (cf. Rowsell \& Wohlwend, 2016).

In Finnish, phonic-based reading instruction may be repetitive and include drilling of sounds and syllables. For this reason, the use of digital literacy games may serve as a motivational tool. However, following Northrop and Killeen (2013), we wish to point out the importance of the teacher's instructions in ensuring that children using literacy apps are actually focusing on the tasks instead of just pushing buttons. The children also need to be explicitly pointed out easy phonological strategies and scaffolding patterns to imitate with each other. For example, they can be shown how to clap hands in word rhythm and how they can then use this strategy in supporting their peers. Scaffolding has its roots in the Vygotskian concept of ZPD, which implies that for sincere scaffolding to occur, the meaningful initiatives of an adult are necessary along with the involvement of a child in an activity that is beyond his/her current understanding. Therefore, assisting children requires a careful calibration of the support provided as well as a process of assessing whether the scaffolded child understands the task at hand (cf. Wood et al., 1976).

A few limitations of the present study are worth mentioning. The results were based on the study of one pre-primary group of fourteen children. More research in a wider range of contexts, languages and age groups is required to capture the variance and development of linguistic and peer-scaffolding strategies. This study shows that by creating suitable scaffolded and supportive environments, digital games may offer circumstances in which support does not necessarily require an expert in literacy development. The children seemed to be able to assist each other even with their still emerging literacy skills.

\section{References}

Aro M and Wimmer H (2003) Learning to read: English in comparison to six more regular orthographies. Applied Psycholinguistics 24: 619-634. doi: $10.1017 / \mathrm{S} 0142716403000316$.

Azevedo R, Cromley J and Seibert D (2004) Does adaptive scaffolding facilitate students' ability to regulate their learning with hypermedia? Contemporary Educational Psychology 29(3): 344-370. doi: 10.1016/j.cedpsych.2003.09.002.

Belland B R, Walker A E, Kim N J (2017) A Bayesian Network Meta-Analysis to Synthesize the Influence of Contexts of Scaffolding Use on Cognitive Outcomes in 
STEM Education. Review of Educational Research, 87(6): 1042-

1081.https://doi.org/10.3102/0034654317723009.

Belz J and Kinginger C (2003) Discourse options and the development of pragmatic competence by classroom learners of German: The case of address forms. Language Learning 53(4): 591-647. https://doi.org/10.1046/j.1467-9922.2003.00238.x

Berelson B (1952) Content Analysis in Communication Research. Michigan: Free Press.

Bernhardt B H and Stemberger J P (1998). Handbook of phonological development. From the perspective of constraint-based nonlinear phonology. San Diego: Academic Press.

Blok H, Oostdam R, Otter ME and Overmaat M (2002) Computer-assisted instruction in support of beginning reading instruction: A review. Review of Educational Research 72: 101-130. https://doi.org/10.3102/00346543072001101.

Bruner J (1990) Acts of meaning: Four lectures on mind and culture. Cambridge, MA: Harvard University Press.

de Guerrero MCM and Villamil OS (2000) Activating the ZPD: Mutual scaffolding in L2 peer revision. The Modern Language Journal 84: 51-68. doi: 10.1111/0026-7902.00052.

Devolder A, Van Braak J and Tondeur J (2012) Supporting self-regulated learning in computer-based learning environments: Systematic review of effects of scaffolding in the domain of science education. Journal of Computer Assisted Learning 28(6): 557-573. doi: $10.1111 /$ j.1365-2729.2011.00476.x.

Donato R (1994) Collective scaffolding in second language learning. In: JP Lantolf and G Appel (eds) Vygotskian Approaches to Second Language Research. Norwood, NJ: Ablex, pp. 33-56.

Eskelä-Haapanen S (2012). Kohdennettu tuki perusopetuksen alkuluokilla. Acta Universitatis Tamperensis 1747. Unit of Education. University of Tampere.

Gallimore R and Tharp R (1990) Teaching mind in society: Teaching, schooling, and literate discourse. In LC Moll (ed) Vygotsky in Education: Instructional Implications and Applications of Socio-historical Psychology. New York: Cambridge University Press, pp. 175-205.

Gibbons P (2002) Scaffolding language, scaffolding learning teaching second language learners in the mainstream classroom. NH: Heinemann, Portsmouth.

Gnadinger CM (2008) Peer-mediated instruction: Assisted performance in the primary classroom. Teachers and Teaching 14(2): 129-142. doi: 10.1080/13540600801965945. 
Griffin ML (2002) Why don't you use your finger? Paired reading in first grade. The Reading Teacher 55(8): 766-774.

Guernsey L, Levine M, Chiong C and Severns M (2012) Pioneering literacy in the digital wild west: Empowering parents and educators. New York, NY: New America Foundation \& Joan Ganz Cooney Center.

Heikkilä R, Aro M, Närhi V, Westerholm J and Ahonen T (2013) Does training in syllable recognition improve reading speed? A computer-based trial with poor readers from second and third grade. Scientific Studies of Reading 17(6): 398-414. doi: $10.1080 / 10888438.2012 .753452$.

Hester E and Hodson B W (2004). The role of phonological representation in decoding skills of young readers. Child Language Teaching and Therapy 20(2): 115-133.

Hirsh-Pasek K, Zosh JM, Golinkoff RM, Gray JH, Robb MB and Kaufman J (2015) Putting education in "educational" apps: Lessons from the science of learning. Psychological Science in the Public Interest 16(1): 3-34. doi: 10.1177/1529100615569721.

Huemer S, Aro M, Landerl Kand Lyytinen H (2010) Repeated reading of syllables among finnish-speaking children with poor reading skills. Scientific Studies of Reading, 14(4): 317-340. doi: 10.1080/10888430903150659.

Israelsson MH (2015) The app map: A tool for systematic evaluation of apps for early literacy learning. The Reading Teacher 69(3): 339-349. doi: 10.1002/trtr.1414.

Jime'nez JE, Herna'ndez-Valle M, Rami'rez G, del Rossario Ortiz M, Rodrigo M, Este'vez A, et al. (2007) Computer speech-based remediation for reading disabilities: The size of spelling-to-sound unit in a transparent orthography. Spanish Journal of Psychology 10: 52-67. https://doi.org/10.1017/S1138741600006314.

Kalantzis M and Cope B (2012) Literacies. Cambridge: Cambridge University Press.

Kozulin A (1990) Vygotsky's Psychology. Hemel Hempstead: Harvester Wheatsheaf.

Kramarski B and Mizrachi N (2006) Online discussion and self-regulated learning: Effects of instructional methods on mathematical literacy. Journal of Educational Research 99(4): 218-230. doi: 10.3200/JOER.99.4.218-231.

Kress G (2003) Literacy in the new media age. London: Routledge.

Kulju P and Mäkinen M (2017) Multilayered word structure model for assessing spelling of Finnish children in shallow orthography. Journal of Research in Reading, 40(3): 254 273. DOI:10.1111/1467-9817.12063. 
Lehtonen A and Bryant P (2001) [The role of syllables in learning to write in Finnish] Tavujen vaikutus lasten kirjoittamaan oppimiseen suomen kielessä. NMI-Bulletin, 11(4): $16-25$.

Li M and Kim D (2016) One wiki, two groups: Dynamic interactions across ESL collaborative writing tasks. Journal of Second Language Writing 31: 25-42. doi: https://doi.org/10.1016/j.jslw.2016.01.002.

Lovio R, Halttunen A, Lyytinen H, Näätänen R and Kujala T (2012) Reading skill and neural processing accuracy improvement after a 3-hour intervention in preschoolers with difficulties in reading-related skills. Brain Research 1448: 42-55. doi: 10.1016/j.brainres.2012.01.071.

Lyytinen H, Aro M, Holopainen L, Leiwo M, Lyytinen P and Tolvanen A (2006) Children's language development and reading acquisition in a highly transparent orthography. In: R Malatesha Joshi and PG Aaron (eds) Handbook of orthography and literacy. New Jersey: LEA, pp. 47-62.

Lyytinen H, Erskine J, Hämäläinen J, Torppa M and Ronimus M (2015) Dyslexia - Early Indentification and Prevention: Highlights from the Jyväskylä Longitudinal Study of Dyslexia. Current Developmental Disorders Reports 2(4): 330-338. doi: 10.1007/s40474015-0067-1.

Lerkkanen M-K (2003) Learning to read. Reciprocal processes and individual pathways. Jyväskylä Studies in Education, Psychology and Social Research, 233. Jyväskylä: University of Jyväskylä.

Lerkkanen M-K, Rasku-Puttonen H, Aunola K \& Nurmi J-E (2004) Predicting reading performance during the first and the second year of primary school. British Educational Research Journal 30(1): 67-92. doi: 10.1080/01411920310001629974.

Lyytinen H, Aro M, Holopainen L, Leiwo M, Lyytinen P and Tolvanen A (2006) Children's Language Development and Reading Acquisition in a Highly Transparent Orthography. In: R Malatesha Joshi and PG Aaron (eds) Handbook of Orthography and Literacy. Mahwah, New Jersery, London: Lawrence Erlbaum Associates, pp. 47-62.

Mäkinen M (2002) Puheen palat ja sanan salat esiopetuksessa. Fonologisen tietoisuuden yhteys alkavaan lukutaitoon. Acta Universitatis Tamperensis 902. Faculty of Education. University of Tampere.

NCC (2016) $=$ National Core Curriculum for Basic Education 2014. Finnish National Board of Education. Publication 2016: 5.

NCCP (2016) = National Core Curriculum for Pre-Primary Education 2014. Finnish National Board of Education. Publication 2016: 6. 
Northrop L and Killeen E (2013) A framework for using iPads to build early literacy skills. The Reading Teacher 66(7): 531-537. doi: 10.1002/TRTR.1155.

Pennala R, Richardson U, Ylinen S, Lyytinen H and Martin M (2013) Computer game as a tool for training the identification of phonemic length. Logopedics Phoniatrics Vocology 39(4): 149-158. doi: 10.3109/14015439.2013.810302.

Pifarre M and Cobos R (2010) Promoting metacognitive skills through peer scaffolding in a CSCL environment. Computer-Supported Collaborative Learning 5: 237-253. doi: 10.1007/s11412-010-9084-6.

Ranjbar N and Ghonsooly B (2017) Peer scaffolding behaviors emerging in revising a written task: A microgenetic analysis. Iranian Journal of Language Teaching Research 5(2): 75-90.

Regtvoort AGFM and van der Leij A (2007) Early intervention with children of dyslexic parents: Effects of computer-based reading instruction at home on literacy acquisition. Learning and Individual Differences, 17: 35-53. doi: 10.1016/j.lindif.2007.01.005.

Reiser B (2004) Scaffolding complex learning: The mechanisms of structuring and problematizing student work. Journal of the Learning Sciences 13(3): 273-304.

Ronimus M and Richardson U (2014) [Digital game-based training of early reading skills: Overview of the GraphoGame method in a highly transparent orthography] Entrenamiento de habilidades de lectura tempranas basado en un juego digital: Vision general del metodo GraphoGame en una ortografia altamente transparente. Estudios de Psicologia 35(3): 648-661. doi: 10.1080/02109395.2014.974424.

Rowsell J and Wohlwend K (2016) Free Play of Tight Spaces? Mapping Participatory Literacies in Apps. The Reading Teacher 70(2): 197-205. doi: 10.1002/trtr.1490.

Saine NL, Lerkkanen M, Ahonen T, Tolvanen A and Lyytinen H (2011) Computerassisted remedial reading intervention for school beginners at risk for reading disability. Child Development 82(3/): 1013-1028. doi: 10.1111/j.1467-8624.2011.01580.x.

Seymour P H K, Aro M and Erskine J M (2003) Foundation literacy acquisition in European orthographies. British Journal of Psychology 94(2): 143-174. doi: $10.1348 / 000712603321661859$.

Siegler RS (2007) Microgenetic analysis of learning: Cognition, perception and language. In: D Kuhn ad RS Siegler (eds) Handbook of Child Psychology. New Jersey: John Wiley \& Sons, Inc, pp. 11-45.

Silvén M, Poskiparta E \& Niemi P (2004) The odds of becoming a precocious reader of Finnish. Journal of Educational Psychology 96(1): 152-164. 
Shooshtari ZG and Mir F (2014) ZPD, Tutor; Peer Scaffolding: Sociocultural Theory in Writing Strategies Application. Procedia—Social and Behavioral Sciences 98: 17711776. doi: 10.1016/j.sbspro.2014.03.605.

Torppa M, Parrila R, Niemi P, Lerkkanen M-K, Poikkeus, A-M et al. (2013).The double deficit hypothesis in the transparent Finnish orthography: a longitudinal study from kindergarten to Grade 2. Reading and Writing 26(8): 1353-1380. doi:10.1007/s11145012-9423-2.

Vygotsky LS (1962) Thought and Language. In: E Hanfmann and G Vakar (eds and trans) Cambridge, MA: The M.L.T. Press.

Vygotsky LS (1978) Mind in society: The development of higher psychological processes. Cambridge, MA: Harvard University Press.

Walsh M (2006) The "textual shift": Examining the reading process with print, visual and multimodal texts. Australian Journal of Language and Literacy 29(1): 24-37.

Wohlwend KE (2015) One screen, many fingers: Young children's collaborative literacy play with digital puppetry apps and touchscreen technologies. Theory Into Practice 54(2): 154-162. doi: 10.1080/00405841.2015.1010837.

Wood D, Burner JS and Ross G (1976) The role of tutoring in problem solving. Journal of Child Psychology and Psychiatry 17: 89-100. doi: https://doi.org/10.1111/j.14697610.1976.tb00381.x. 